\title{
A figura humana, a modelagem, a construção e o entalhe: \\ A escultura pública de Neusa Moraes
}

Anahy Mendonça Jorge ${ }^{1}$

DOI 10.20396/eha.vil4.3394

Uma pesquisa sobre a escultura goiana: Neusa Moraes

O presente artigo se insere dentro do projeto de pesquisa: Atelier Aberto de Cerâmica que visa, entre alguns objetivos teóricos e práticos, estudar os processos artísticos de escultores brasileiros. Dentro desse contexto, vamos nos orientar pela análise do processo artístico adotado pela escultora goiana Neusa Moraes. Nesse caminho, a observação do desenrolar da obra será importante para compreender a presença da figura humana e de procedimentos da escultura tradicional como a modelagem, a construção e o entalhe.

Metodologicamente, nós vamos utilizar a Ciência Poiética² que segue passo á passo as diferentes etapas da criação. Essa ciência focaliza a obra se fazendo, nos permitindo conhecer as conotações subjetivas ali inseridas; diluídas em meio as inúmeras ações empreendidas pelo artista. Para o desenvolvimento dessa pesquisa foram utilizadas as seguintes ferramentas metodológicas: entrevistas, análise de fotografias, escritos e depoimentos dos artistas.

O estudo do processo artístico da obra escultória será importante para conhecer e entender os procedimentos escutóricos utilizados (a modelagem, a construção e o entalhe) e a interface da figura humana como veículo de expressão dentro da escultura. Estudar o processo artístico das obras atuais escultóricas possibilita a percepção dos indícios das possíveis significações ali inseridas, o pensamento materializado e compreendendo assim que a obra vai além de sua finalização.

A figura humana na escultura de Neusa Moraes

A figuração aparece na obra pública da escultora Neusa Moraes, em especial na obra que

1 UFG; Doutorado em Estudos e Práticas das Artes/UQAM.

2 PASSERON, René. La naissance d`Icare. Paris: aezcg Éditions, 1996, 
iremos focalizar: o Monumento á Construção de Goiânia³. Ele é constituído de três esculturas figurativas em tamanho monumental reproduzidas em bronze; uma grande coluna retangular com quatro lados distintos e inclinados em relação ao solo; e um pedestal de sete degraus separando o grupo escultórico do nível do solo .

Descrevendo a obra (Figura 01), nós percebemos que as figuras escultóricas em metal estão em dimensão maior que a escala humana mas bem menores que a coluna retangular de pedras. Tais figuras estão posicionadas ao redor das quatro faces expressando, de forma metafórica, o envolvimento das três raças para a construção da cidade e Goiânia: o negro, o índio e o branco. Como falar dessas questões sem o uso da gestualidade do corpo humano?! Mais que ser uma representação mimética de uma realidade, os corpos modelados vão ser veículos de significações, representando a ideia do que a artista pensava sobre esse importante momento social. A obra materializa-se por meio do figurativo e confunde-se na composição escultórica com outros elementos expressivos. Segundo os estudos de H.R. Rookmaaker ${ }^{4}$ a arte figurativa não constitui de uma imitação da natureza mas "representa uma experiência humana, uma interpretação humana".

Podemos dizer que através da materialidade a obra fala da imaterialidade, a grande coluna presente nesse conjunto nos apresenta algumas significações: nas linha retas ela suscinta o conceito de força e rigidez; por meio de seu posicionamento inclinado, traz a ideia de instabilidade, de tensão e movimento; a coluna é pontilhada de pontos em preto e branco, trazendo uma noção de diversidade, homogeneidade e unidade numa mesma forma; suas quatro faces ásperas representam metaforicamente as dificuldades que todos enfrentaram nesse processo de construção (Figura 02).

Analisando a composição percebemos que as figuras falam de duas formas: por meio do movimento corporal em si, no aumento proposital das mãos; e na relação estabelecida com a coluna inclinada. Em relação ao elemento coluna, as três figuras vão desenvolver o mesmo esfoço em posições diferentes. A figura do homem branco está identificado pelas características faciais e é o único que porta calças longas e sapatos; seu corpo contrapõe e impulsiona o levantamento da grande coluna de cimento. Ao lado esquerdo e posicionado-se junto ao elemento branco, encontramos o negro (vestido de calção e de pés descalsos); estabelecendo uma interface corporal mais intensa, o mãos e ombro, com a coluna, impulsionando a rídida pilastra para frente. Espacialmente,

\footnotetext{
3 Esse conjunto escultórico está inserido na principal praça da cidade de Goiânia, a Praça Cívica, em frente ao Palácio das Esmeraldas. A obra foi inaugurada em 1968 e constitui de um signo da cidade de Goiânia.

4 Rookmaaker, H. R. A arte moderna e a morte de uma cultura. Viçosa: Ultimato. 1994, pág 26.
} 


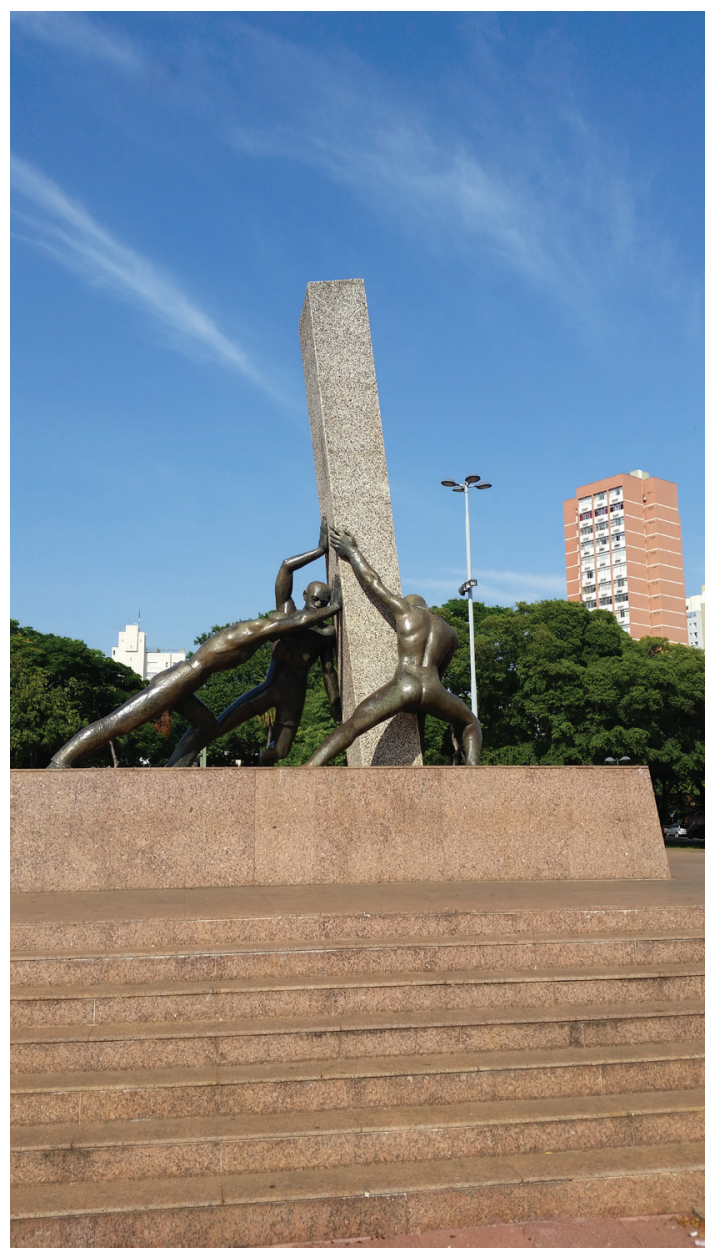

[Figura 01] Neusa Moraes. O Monumento a Construção de Goiânia. 1967. Goiânia.

Fonte: Anahy Jorge

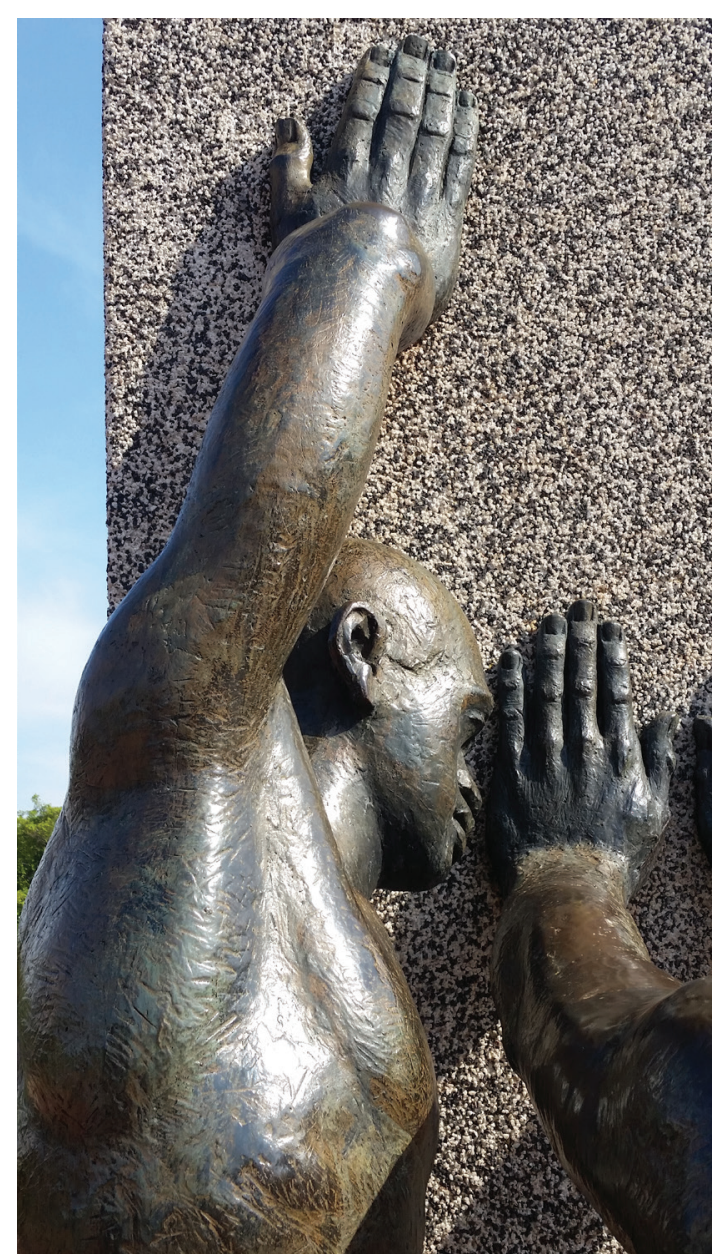

[Figura 02] Neusa Moraes. OMonumento a Construção de Goiânia. 1967. Goiânia.

Fonte: Anahy Jorge

[Figura 03]

Neusa Moraes. Aquarela do Brasil no Apocalipse.

1989. Goiânia.

Fonte: Matheus Nhan Deru.

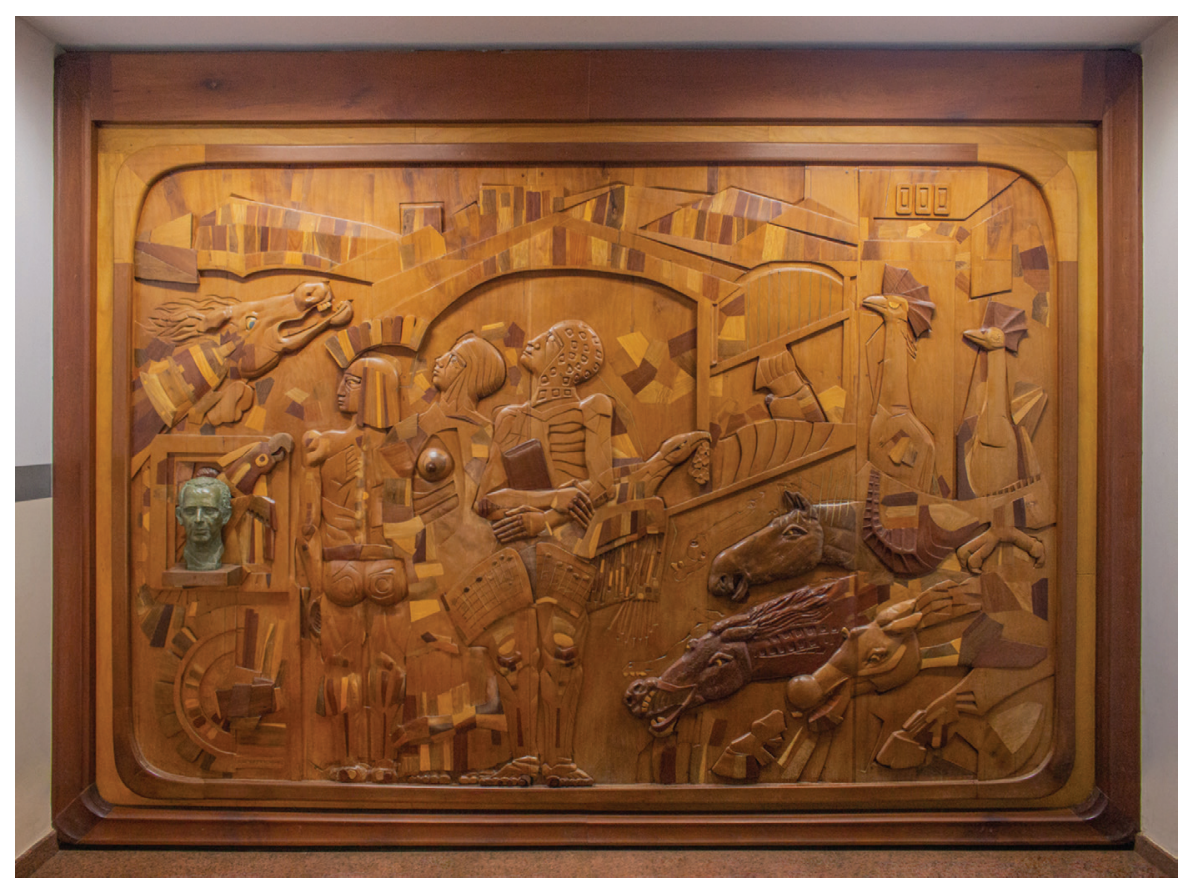


o elemento que representa o índio constitui a figura que se insere, ao mesmo tempo, na lateral e frente da coluna rígida. É a única figura que se insere na parte frontal, aquela que leva o emblema da cidade no alto, simbolizando talvez o elemento que aqui esteve inicialmente. Isso nos faz pensar que há um sentido temporal envolvendo as faces da grande coluna (face posterior, laterais e frente) simbolizando a chegada e ação de cada elemento junto a esse processo de levantamento da grande coluna retangular, metáfora da construção da cidade. Independente desse estar na frente ou atrás, o esforço e introspecção de cada figura a seu modo acentua a noção de coletividade, de conjunto e objetivo comum.

Á rigidez da coluna, a escultora contrapõe linhas sinuosas dos corpos humanos representado o negro, o índio e o branco, criando movimento e dinamismo na composição. As formas arredondadas pela modelagem do gesso e o brilho do bronze ganham aspecto lúdico e ficam em um plano superior separados do nível do solo por um conjunto de sete degraus. Nesse processo, o resultado obtido pelo conjunto escultórico junto ao público traduz as intenções da escultora que, na ocasião de sua inauguração, dizia "ela foi criada para ser tocada pelas pessoas"s.

A modelagem em gesso no Monumento das Três Raças e suas influências

A modelagem constitui de um dos quatros procedimentos escultóricos tradicionais e se apresenta como um método de adição. Ou seja, o artista trabalha adicionando e retirando matéria dúctil até chegar na forma final. Dentro o conjunto de materiais oriundos do contexto da modelagem, vamos encontrar o gesso.

O entalhe constitui de um segundo procedimento, de subtração, que retira matéria dura pelo método do desbaste. Nesse contexto vamos perceber que vários materiais oriundos da natureza se inserem dentro desse procedimento, como o granito, o mármore, a madeira e a pedra sabão. A construção é um procedimento atual que caracteriza-se por apresentar um aglomerado de partes (semelhantes ou não) que se unem por intermédio de vários dispositivos de união.

A formação acadêmica de Neusa Moraes envolveu o conhecimento processual da escultura na Escola de Belas Artes de São Paulo . Ainda como estudante, ela vai participar de algumas exposições em São Paulo, entre elas citamos as duas edições do importante Salão Paulista de Arte

\footnotetext{
5 Hamu, Ademir. De Goyaz a Goiás. Goiânia: AMS Gráficas e editora, 2019, pág. 359.

6 A Academia de Belas Artes de São Paulo foi criada em 1926, em meio a criação de várias instituições como o Teatro Municipal, o Conservatório Dramático e Musical de São Paulo e a Academia Paulista de Letras e da Companhia Dramática de São Paulo.
} 
Moderna $^{7}$, nas edições de 1958 e 1960. Ela vai receber a encomenda do Monumento á Construção de Goiânia ainda enquando estudava em São Paulo. Visando um acompanhamento na elaboração do monumento, ela tenta inicialmente a orientação do professor Custav Ritter ${ }^{8}$, na ocasião professor da Faculdade de Artes da Universidade Federal de Goiás. No entanto, ele a orienta a procurar os professores italianos do curso de Escultura da Academia de Belas Artes de São Paulo.

Observando a coleção de fotografias que documentam o processo artístico do monumento vamos observar que a artista vai utilizar etapas, como: desenhos; maquete em gesso; execução dos modelos figurativos monumentais a partir de uma estrutura de ferro central e fios de palha ou madeira reciclada; e a modelagem posterior de camadas de gesso proporcionará o acabamento de cada escultura. Esse processo viabilizou a realização da modelagem das formas arredondadas que encontramos no bronze. As figuras em gesso foram encaminhadas posteriomente para a reprodução da obra via moldagem em gesso e posterior fundição.

Em meio a um processo complexo de elaboração de uma escultura pública, vamos nos ater somente ao contexto da modelagem. Segundo os estudos de Florence Mèredieu ${ }^{10}$ as características da modelagem se aproxima do conceito de assemblagem, ou seja método de adição, auto-aderente, embasado nas características da plasticidade e de elasticidade do material. Inicialmente, o gesso apresenta uma humidade, uma textura granulosa que, com acréscimos, vai formando uma casca endurecida. A modelagem constitui de um processo sem forma conclusiva natural, não possui um limite externo distintivo. $\mathrm{O}$ ato de modelar, tirar e/ou inserir massa, se move em direção ao espaço do espectador ${ }^{11}$. Esse processo dá oportunidade ao artista de veicular com maior facilidade suas ideias no contexto do volume escultórico.

Vamos apresentar quatro artistas escultores mencionados por ela em uma entrevista realizada em 1998. Dentre eles, dois serão professores que pertenceram a Escola de Belas Artes de São Paulo, Raphael Galvez (1907-1998) e Júlio Guerra (1912-2001); um será o escultor paulista Humberto Carpinelli; e o escultor e professor alemão radicado no Brasil Gustav Henning Ritter (1904-1979).

Observando a escultura em gesso intitulada "O Brasileiro", de Raphael Galvez², nós perce-

\footnotetext{
7 O Salão Paulista de Arte Moderna começa a funcionar em 1951.Disponível em: <http://enciclopedia.itaucultural.org.br/evento80504/140salao-paulista-de-arte-moderna7

8 O escultor e professor de escultura Bening Gustav Ritter foi professor das duas escolas de artes que Goiânia comportou: a Escola Goiana de Belas Artes (ECBA) e Instituto de Belas Artes de Coiás (IBAG).

9 Entrevista com a artista em fevereiro de 1998.

10 Mèredieu, Florence de. Histoire matérielle et immatérielle de l’art moderne. Paris: Bordas Cultures, 1994, pág 104.

11 Read, Herbert. Escultura Moderna, uma história concisa. São paulo: Martins fontes, 2003, pág 7

12 O escultor Raphael Galvez possui 5 monumentos públicos.
} 
bemos a força da sua modelagem pelo volume alcançado e o cuidado dado aos detalhes faciais discutindo o conceito de miscigenação; apresentando a monumentalidade por meio do domínio do corpo humano e, ao mesmo tempo, o interesse em acentuar as extremidades, pés e mãos. Ele foi professor da referida escola entre 1957 a 1976.

Outro escultor da Escola de Belas Artes de São Paulo é Júlio Guerra ${ }^{13}$, autor da escultura de "Borba Gato" (1963) localizada na entrada de Santo Amaro. Nessa produção escultórica pública vamos observar a presença da modelagem em gesso; o gosto pela escultura figurativa monumental; o interesse pela mistura de procedimentos (modelagem, entalhe e construção); inclusão de materiais como pedras coloridas trazidas de vários lugares do Brasil, cortadas por ele e dispostas no fundo dos moldes e envolvidas com camadas de cimento; abordagem de temas como a indentidade nacional; e o desejo de aproximação com o público.

Outro artista escultor a ser mencionado é Humberto Carpinelli. É de sua autoria o "Monumento do Brigadeiro José da Silva Paes" (1939) na cidade de Rio Grande. A composição desse monumento apresenta uma coluna de granito em posição vertical e um conjunto de esculturas figurativas distribuídas ao redor das quatro faces do elemento central, uma coluna quadrangular. As figuras apresentam a participação do processo de modelagem em gesso com uma superfície mais detalhada e lisa, traduzindo um maior realismo. Ele vai se interessar pelos seguintes temas: a identidade nacional e a construção de uma sociedade com a participação das três raças, o negro, o branco e o índio. O conjunto escultórico envolverá o pedestal possibilitando a proximidade com o público e sugerindo uma interface maior entre a a escultura e o público.

A partir de 1972, Neusa Moraes adentra no contexto acadêmico da Faculdade de Artes Visuais na cadeira de modelagem e plástica. Nesse percurso, a obra abstrata do professor Gustav Henning Ritter desenvolvendo uma pesquisa com placas finas e bem polidas, unidas pela construção e envolvendo o espaço circundante vai instigar a pesquisa de Neusa Moraes junto ao entalhe em madeira.

Em 1992, ela vai elaborar o painel da Escola Técnica de Coiás intitulado "Aquarela do Brasil no Apocalipse', (Figura 03). Essa obra trará os resultados provenientes de sua pesquisa no entalhe de madeiras brasileiras, explorando e documentando mais de trinta e dois tipos de fragmentos coletados. Nesse processo, emege a policromia por meio dos diferentes tons e texturas. Assim, a obra se 
materializa com a junção de frangmentos (construção), com posterior entalhe das formas e, inserção do elemento em bronze. Uma pesquisa que procura por intermédio da policromia e construção alargar as possibilidades de cruzamento entre os procedimentos do entalhe e da modelagem.

A figuração continua a prevalecer nessa obra através do entalhe das figuras do negro, índio e branco; de figuras de animais; e da presença do busto em bronze do tio, uma homenagem da artista ao familiar que a criou. Nesse trabalho, vamos observar experimentações na escultura em relevo, explorando tanto a forma e quanto a cor; e o cruzamento em uma mesma obra dos procedimentos tradicionais, como a modelagem, a fundição, a construção e o entalhe. (Figura 03)

\section{Conclusão}

Processualmente, a artista desenvolveu sua pesquisa explorando os quatro procedimentos tradicionais da escultura: modelagem, entalhe, construção e fundição. Isso foi importante para que chegássemos a algumas considerações como: o procedimento da modelagem em gesso foi pontual para que conhecêssemos a participação da figuração que, para além da mera representação da realidade, constitui meio eficaz para verbalizar os conteúdos expressivos, veículando o pensamento individual da artista em relação ao contexto histórico e social da construção da cidade de Goiânia. Essa produção se forma a partir de um pensar que passa por essa interface existente entre o artista e a realidade mas que usa de outros elementos para completar sua idéia.

Aqui apresentamos duas obras de Neusa Moraes: o "Monumento á Construção de Goiânia" e "Aquarela do Brasil no Apocalipse". Essa pesquisa levou-nos a conhecer as possibilidades e recursos existentes junto aos procedimentos escultóricos tradicionais, através das possibilidades ofertadas por cada matéria e as possíveis interações entre elas. Nesses trabalhos, a figura humana vai ser apresentada em uma forma ás vezes simplificada e despojada de detalhes; a monumentalidade vai estar presente tanto nos detalhes e quanto na grande dimensão, envolvendo assim o público; sua escultura vai almejar um maior contato entre o público e a escultura. Para além de um objetivo representativo, a artista almeja por meio da sua figuração inserir seu pensamento sobre a importância do trabalho individual e conjunto de cada uma das três raças para a construção de Coiânia.

Por meio de seus trabalhos, vamos observar os desdobramentos de seu pensar e das influências que naturalmente recebeu de outros artistas, modificou com suas próprias experiências e, posteriormente, repassou de forma generosa a todos que pleitearam junto á ela, a oportunidade de estudar a linguagem da escultura. 
Referências Bibliográficas

AUCÊ, Anahy Mendonça Jorge. Imagem Símbolo: função da escultura figurativa urbana. 1998. Dissertação (Mestrado em Comunicação e Produção Simbólica) - Escola de Comunicação e Artes/USP - Universidade Federal de Goiás, Goiânia, 1998.

CABRAL, Maria Madalena Roberto \& BORGES, Maria Elízia. Monumento a Goiânia: outro olhar sobre sua trajetória. IN: https://seminarioculturavisual.fav.ufg.br/up/778/o/2009.GT1_CABRAL_e_BORGES_-_MONUMENTO_A_GOIANIA_OUTRO_OLHAR_SOBRE_SUA_.pdf

GOMBRICH, E. H. A História da Arte. Rio de Janeiro: Zahar Editores, 1980.

HAMU, Ademir. De Goyaz a Goiás, Volume 2. Goiânia: AMS Gráficas e editora, 2019.

MÈREDIEU, Florence de. Histoire matérielle et immatérielle de l'art moderne. Paris: Bordas Cultures, 1994.

PASSERON, René. La naissance d'Icare. Paris: ae2cg Éditions, 1996.

READ, Herbert. Escultura Moderna, uma história concisa. São paulo: Martins fontes, 2003.

ROOKMAAKER, H. R. A arte moderna e a morte de uma cultura. Viçosa: Ultimato. 1994.

WITKOWER, Rudolf. Escultura. São Paulo: Martins Fontes, 1991. 